\title{
EXPLAINING POLITICS, NOT POLLS \\ REEXAMINING MACROPARTISANSHIP WITH \\ RECALIBRATED NES DATA
}

\author{
JAMES E. CAMPBELL*
}

\begin{abstract}
Like all surveys, the American National Election Studies (NES) imperfectly reflects population characteristics. There are wellknown differences between actual and NES-reported turnout rates and between actual and NES-reported presidential vote divisions. This research seeks to determine whether the aggregate misrepresentation of turnout and vote choice affects the aggregate measurement of party identification: macropartisanship. After NES data are reweighted to correct for turnout and vote choice errors, macropartisanship is found to be more stable, to be less sensitive to short-term political conditions, and to have shifted more in the Republican direction in the early 1980s. The strength of partisanship also declined a bit more in the 1970s and rebounded a bit less in recent years than the uncorrected NES data indicate.
\end{abstract}

According to the American National Election Studies (NES), 77.6 percent of eligible Americans turned out to vote in the 2008 presidential election. Barack Obama received 54.8 percent to John McCain's 45.2 percent of the two-party popular vote. This is what the NES data indicate, but this is not what happened. By our best counts, turnout was 61.7 percent of the voting-eligible population, Obama received 53.7 percent, and McCain received 46.3 percent of the two-party popular vote.

Despite inaccuracies of this sort, the NES remains the "gold standard" of survey data to scholars of American elections. NES data are routinely reported

JAMES E. CAMPBELL is Professor and Chair of the Department of Political Science, University at Buffalo, State University of New York, Buffalo, NY, USA. The data used in this study were made available by the American National Election Studies (NES) with funding since 1977 from the National Science Foundation. I wish to thank the NES, the NSF, and the Survey Research Center and the Center for Political Studies at the University of Michigan for collecting and distributing these data. I also thank Congressional Quarterly and Michael McDonald and the United States Election Project for collecting and making available the vote division and turnout data that were used in this study. *Address correspondence to James E. Campbell, Department of Political Science, 520 Park Hall, University at Buffalo, SUNY, Buffalo, NY 14260, USA; e-mail: jcampbel@buffalo.edu. 
as what the electorate thinks and does, what affects that thinking and behavior, and how the electorate's thinking and behavior has changed over time (Abramowitz 2004; Abramson, Aldrich, and Rohde 2005; Jamieson 2000, 14, 82; Keith et al. 1992, 14; Lewis-Beck et al. 2008; Martinez and Gill 2005). However, like all survey data, and as the 2008 example illustrates, NES data are imperfect. Sampling error, nonresponse rates, measurement errors, framing effects, question-wording sensitivities, respondent misreporting, and various other problems produce errors in surveys that make them less than perfectly representative of political reality (Clausen 1968-69; Crespi 1988; Asher 2007). ${ }^{1}$ In general, students of public opinion and voting behavior assume that these errors are small and do not significantly affect their analyses.

The general question posed in this article is whether the known inaccuracies of NES studies regarding aggregate turnout and presidential vote choice, the two most important electoral behaviors, significantly affect the NES accounts of other aggregate-level political attributes related to turnout and vote choice. In particular, do the known errors in aggregate turnout and vote choice appreciably affect the NES's aggregate measure of party identification, macropartisanship? Since there are well-established associations between the strength of party identification and the decision to turn out to vote, and between party identification and the vote choice at the individual level (Campbell et al. 1960; Lewis-Beck et al. 2008), and parallel associations between aggregate partisanship and both the national vote division (Converse 1966; Abramson and Ostrom 1991; Erikson, MacKuen, and Stimson 2002) and turnout levels (Abramson and Aldrich 1982; Rosenstone and Hansen 2003), there are strong reasons to suspect that errors in the distribution of turnout and the presidential vote would also generate errors in the aggregate distribution of partisanship. More specifically, we should expect that whichever party is overrepresented in the presidential vote is also overrepresented in party identification, and that the general underrepresentation of nonvoters in NES data underrepresents weaker partisans and independents who are less likely to vote. Put differently, since most partisans vote for their party's presidential candidate, if voters for a candidate are underrepresented among survey respondents, then the partisans who voted for that candidate are probably also underrepresented. These remain suspicions, however, because unlike aggregate turnout and the presidential vote division, there is no external benchmark for aggregate partisanship that makes the errors in its measurement obvious. ${ }^{2}$ This study tests these suspicions by reweighting NES data to bring them into line with the actual aggregate benchmarks of

1. Clausen $(1968-69,591)$ also observes that a portion of the discrepancy between NES measures and the actual electorate is a function of NES's definition of the "sample universe" as something other than all eligible voters. The NES's sample universe excludes a number of potential voters (e.g., hospital patients, nursing home residents, hotel residents).

2. This study concerns only the accuracy of survey measurements of turnout, vote choice, and partisanship, and not the causal relationships among these variables. 
the presidential vote and turnout distributions, in order to measure more accurately macropartisanship and its change over time.

The analysis makes four points. First, though often regarded as small in absolute terms and within the normal bounds of sampling error, NES's errors with respect to presidential vote choice and turnout are not trivial, because the scale of real change in American politics also involves only "small-scale shifts around the middle" (Stimson 2004, 159). Second, aggregate presidential vote choice errors are highly variable from one election to the next. This distorts over-time estimates of aggregate political change. Third, both the turnout and presidential vote choice data errors can be corrected (or at least mitigated) by reweighting the data to the known population parameters of turnout and the presidential vote choice. Such corrections are routinely performed to correct for the under- or overrepresentation of demographic characteristics (race, gender, etc.) and of political variables in exit polls (McDonald 2007). Fourth, the corrected NES data, brought into line with the known population parameters of turnout and presidential vote choice, produce significant changes in the distribution and dynamics of macropartisanship.

These changes produced by the corrections in NES data have important implications for two debates about macropartisanship. The first concerns the stability of macropartisanship and its sensitivity to short-term political conditions. Both Erikson, MacKuen, and Stimson $(1989$; 2002) and BoxSteffensmeier and Smith (1996) find macropartisanship to be quite changeable and sensitive to the recent performance of the parties. On the other hand, Abramson and Ostrom (1991) and Green, Palmquist, and Schickler (2002) find macropartisanship to be stable and largely insensitive to shortterm conditions. The second debate concerns the existence of long-term or realigning changes in macropartisanship. Erikson, MacKuen, and Stimson (2002) find that macropartisanship changes continually, as in a "moving equilibrium," rather than through the punctuated change of realignments. This view challenges the conventional wisdom about realignments rooted in the early work of Key $(1955 ; 1959)$ and Burnham $(1970)$ and the later research by Meffert, Norpoth, and Ruhil (2001) that found a realignment in macropartisanship in the 1980s.

The following sections take the analysis through three steps. First, the extent of the NES errors in turnout and vote choice is examined. Second, the assumptions required to adjust or reweight NES data are identified, and the weights are calculated and applied to the data. Third, the distribution and dynamics of party identification in the corrected and uncorrected NES data are compared. Details about the NES data and the questions used in this study may be found in Appendix 1 . 


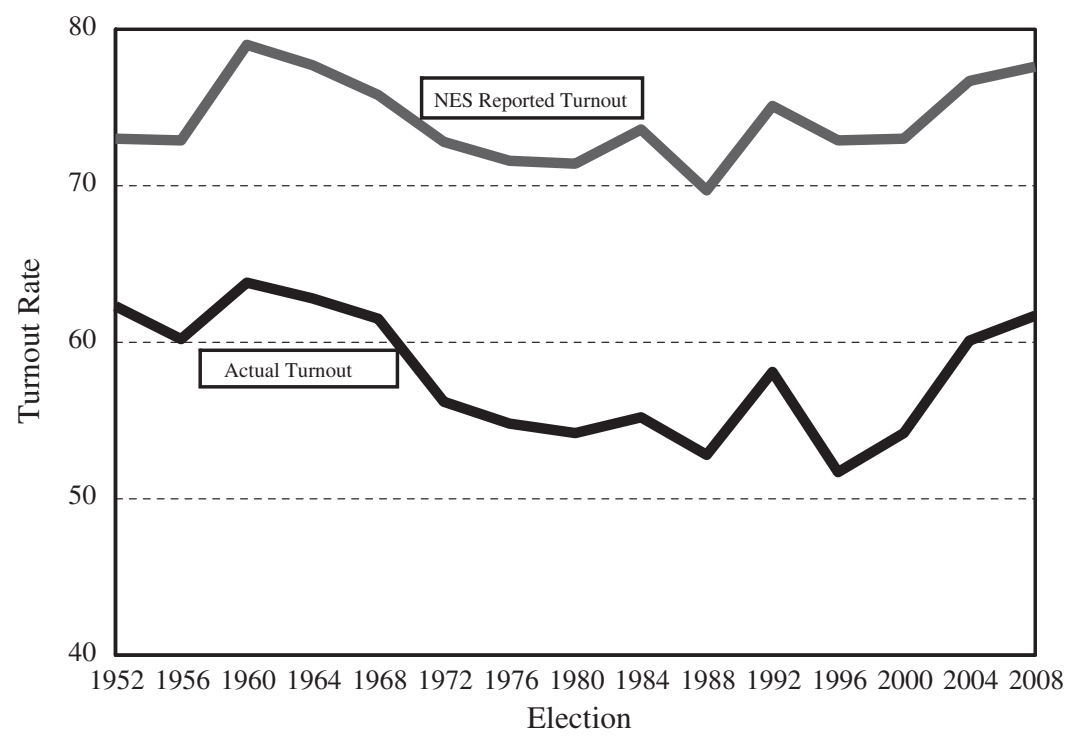

Figure 1. Actual and Reported Voter Turnout in Presidential Elections, 1952-2008. The NES reported turnout rate was calculated from the NES Cumulative Data File variable VCF0702 using weight variable VCF0009A and the May 2009 release of the 2008 NES data. The actual voter turnout rate is of the voting eligible population and is from McDonald and Popkin (2001 and McDonald 2009).

\section{The Size of NES Turnout and Vote Choice Errors}

Are the differences between the reported and actual turnout and presidential vote distributions large enough to matter? With respect to turnout, the answer would appear obvious. Even after considering the complication of some nonvoters misreporting that they voted, differences between actual and reported turnouts are large. And, though generally small in absolute terms, differences between the actual and NES reported presidential vote divisions are also nontrivial when compared to actual vote margins and the change in the actual vote from one election to the next.

Figure 1 displays the well-known large discrepancy between actual and NES-reported turnout rates in presidential elections from 1952 to $2008 .^{3}$ As

3. These data were collected and distributed by the American National Election Studies (www. electionstudies.org): the 1948-2004 ANES cumulative data file [dataset], Stanford University and the University of Michigan [producers and distributors], 2005, and supplemented with 2008 NES data. The NES data were initially weighted by variable VCF0009A. The variables used in this study are the presidential vote variable VCF0705 (except for the two-party vote analysis in Tables 1-3, in which VCF0704 was used), the turnout variable VCF0702, and the party identification variable VCF0301. The same variables are also examined in the 2008 NES data. 
Table 1. Reported and Actual Two-Party Vote for Presidential Candidates, 1952-2008

\begin{tabular}{lccc}
\hline & \multicolumn{2}{c}{ Democratic Presidential Two-Party Vote Percentage } \\
\cline { 2 - 4 } Election & Reported & Actual & Difference \\
1952 & 41.94 & 44.60 & -2.66 \\
1956 & 40.36 & 42.25 & -1.98 \\
1960 & 49.19 & 50.08 & -0.95 \\
1964 & 67.51 & 61.34 & +6.29 \\
1968 & 46.21 & 49.60 & -3.38 \\
1972 & 35.67 & 38.21 & -2.53 \\
1976 & 51.13 & 51.05 & +0.07 \\
1980 & 43.67 & 44.70 & -1.03 \\
1984 & 41.79 & 40.83 & +0.96 \\
1988 & 47.11 & 46.10 & +1.01 \\
1992 & 58.52 & 53.46 & +4.98 \\
1996 & 58.46 & 54.74 & +3.65 \\
2000 & 52.03 & 50.27 & +1.79 \\
2004 & 49.87 & 48.77 & +1.12 \\
2008 & 54.83 & 53.68 & +1.15 \\
Mean absolute error of reported presidential vote percentage & \pm 2.24 \\
\hline
\end{tabular}

NOTE.-The vote percentages are of major-party presidential voters. The reported votes are from the American National Election Studies (www.electionstudies.org), the 1948-2004 ANES cumulative data file [dataset], Stanford University and the University of Michigan [producers and distributors], 2005; and the ANES 2008 Time Series Study, May 11, 2009, version. The vote is calculated from Congressional Quarterly's Guide to U.S. Elections (2005) and Dave Leip (2009).

Burden (2000) observes, the reported versus actual turnout gap increased from a low of 11 percentage points in 1952 to a high of about 25 points in 1996. A gap of this magnitude may produce significant distortions in a number of the electorate's characteristics related to voting or abstention. However, the consequences of the NES turnout error for measures of other responses (e.g., party identification) are attenuated by the fact that a significant portion of the discrepancy is the result of nonvoting respondents misreporting that they voted. In effect, NES data look less representative of the views of nonvoters than they really are because a number of reported voters are actually nonvoters. The exact extent of misreporting is unknown (since the voter validation studies were indeterminate about the records for some respondents), but estimates range from as low as four or five percent to as high as 11 to 14 percent. A reasonable estimate of misreporting is probably in the seven to 10 percent range. This still leaves nonvoters significantly underrepresented among respondents (by as many as 14 percentage points), and their characteristics other than nonvoting may be underrepresented as well.

Table 1 presents the actual and the NES-reported presidential two-party popular vote percentages for Democratic presidential candidates from 1952 
Table 2. Actual, Reported, and Error in Vote Margin for Plurality Candidates, 1952-2008

\begin{tabular}{lcccc}
\hline Election & $\begin{array}{c}\text { Actual } \\
\text { Two-Party } \\
\text { Vote Margin }\end{array}$ & $\begin{array}{c}\text { Reported } \\
\text { Two-Party } \\
\text { Vote Margin }\end{array}$ & $\begin{array}{c}\text { Absolute Error } \\
\text { in Reported } \\
\text { Vote Margin }\end{array}$ & $\begin{array}{c}\text { Reported Vote Margin } \\
\text { Error as \% of Actual } \\
\text { Vote Margin }\end{array}$ \\
\hline 1952 & 5.41 & 8.06 & 2.66 & 49 \\
1956 & 7.75 & 9.64 & 1.98 & 26 \\
$1960^{*}$ & 0.08 & -0.81 & 1.12 & wd \\
1964 & 11.34 & 17.51 & 6.29 & 55 \\
1968 & 0.41 & 3.79 & 3.38 & 835 \\
1972 & 11.79 & 14.34 & 2.53 & 21 \\
1976 & 1.05 & 1.13 & 0.07 & 6 \\
1980 & 5.30 & 6.33 & 1.03 & 19 \\
1984 & 9.17 & 8.21 & 0.96 & 11 \\
1988 & 3.90 & 2.89 & 1.01 & 74 \\
1992 & 3.46 & 8.52 & 4.98 & 676 \\
1996 & 4.74 & 8.46 & 3.65 & 90 \\
2000 & 0.27 & 2.03 & 1.79 & 31 \\
2004 & 1.24 & 0.13 & 1.12 & $148^{*}$ \\
2008 & 3.69 & 4.83 & 1.15 & 40 \\
Abs. Mean & 4.64 & 6.45 & 2.24 & \\
Abs. Median & 3.90 & 6.33 & 1.79 & \\
\hline
\end{tabular}

NOTE.-See table 1 for sources. The plurality candidate received the plurality of the total popular vote. In each instance, excepting 2000, this was the candidate winning the electoral vote majority. The actual and NES-reported two-party vote margins for these candidates are the candidate's percentage of the two-party popular vote minus 50 percent. *The 1960 election is excluded from the analysis of the ratio of errors to the real vote margin, since the reported vote margin in that election was in the wrong direction (favoring Nixon over Kennedy). Excluding the 1964 case, the absolute mean actual vote margin is 4.16 and the absolute mean reported margin is 5.66.

to 2008. From one perspective, the errors look like normal sampling errors and are nothing about which to be concerned. The mean absolute error is 2.2 percentage points. Though errors in the reported vote are substantial in several elections (most notably 1964, but also 1968, 1992, and 1996), the errors are smaller than two percentage points in nine of the 15 elections.

Though these vote division errors (except for 1964) at first appear harmless (Gronke 1992; Wright 1993, 294), they are cast in a different light when set against important parameters of the actual aggregate vote. Table 2 reports the vote division errors in relation to actual presidential vote margins. Compared to actual vote margins, the NES vote division errors are substantial. The mean absolute NES vote division error of 2.2 percentage points is about half the size of the mean actual vote margin (4.6 percentage points). In some elections, the 
Table 3. Actual and Reported Vote Change between Elections, 1952-2008

\begin{tabular}{lccc}
\hline Actual Two-Party & $\begin{array}{c}\text { Vote Change for } \\
\text { the Democratic } \\
\text { Candidate }\end{array}$ & $\begin{array}{c}\text { Reported Two-Party } \\
\text { Vote Change for } \\
\text { the Democratic } \\
\text { Candidate }\end{array}$ & $\begin{array}{c}\text { Error in Reported } \\
\text { Vote Change }\end{array}$ \\
\hline 1952 & -7.72 & -12.42 & 4.69 \\
1956 & -2.35 & -1.58 & -0.77 \\
1960 & 7.84 & 8.83 & -0.99 \\
1964 & 11.26 & 18.32 & -7.06 \\
1968 & -11.75 & -21.29 & 9.55 \\
1972 & -11.38 & -10.55 & -0.84 \\
1976 & 12.84 & 15.47 & -2.63 \\
1980 & -6.36 & -7.46 & 1.11 \\
1984 & -3.87 & -1.88 & -1.98 \\
1988 & 5.27 & 5.33 & -0.06 \\
1992 & 7.36 & 11.41 & -4.05 \\
1996 & 1.28 & -0.06 & 1.34 \\
2000 & -4.47 & -6.43 & 1.96 \\
2004 & -1.51 & -2.16 & 0.65 \\
2008 & 4.93 & 4.96 & 0.03 \\
Abs. Mean & 6.68 & 8.54 & 2.51 \\
Abs. Median & 6.36 & 7.46 & 1.22 \\
\hline
\end{tabular}

NOTE.-See table 1 for sources. Excluding the 1964 and 1968 elections drops the mean actual absolute change to 5.94 and the mean reported absolute change to 6.81. Excluding these two elections drops the mean error in the reported vote change to 1.61 percentage points.

NES error as a proportion of the actual margin is quite large. ${ }^{4}$ Some of these are close elections in which even a modest NES error generates a large ratio of error to margin (e.g., 2004), but others are in elections that were not especially close. In 1952, for instance, Eisenhower won with a 5.4-percentage-point margin (55.4 percent), but NES had his margin at 8.1 points. The 2.7-point error reports Eisenhower's margin at about half again its actual size. The error in 1996 is also quite large compared to the actual margin. President Clinton defeated Senator Dole by a healthy margin that year, but not by the landslide of the NES-reported vote.

4. In many cases there seems to be a winner's bias, i.e., the winning candidate's vote margin is inflated in the NES study (Wright 1993). However, this is not a consistent bias. In four of the 14 elections in which there was a clear post-election plurality winner (setting aside the disputed 2000 election), the reported vote overrepresented votes for the losing candidate (1960, 1984, 1988, and 2004). It may be that any winner's bias on a matter as salient as the presidential vote reflects an undercount of the losing candidates' supporters rather than a misreporting of the vote. Those supporting the losing candidate may be less inclined to participate in the post-election survey. 
The variability of NES errors in the vote division also causes them to be of concern in examining voting dynamics. The actual and NES-reported presidential vote change from one election to the next is reported in table 3. It shows that the NES series is more volatile than the actual vote. The actual mean vote shift between elections since 1952 is 6.7 percentage points. The NES-reported vote shift is 8.5 percentage points. Adding to concerns about the unrepresentative volatility in the vote is that the NES errors are quite variable. In some elections, the NES data are approximately on target for vote change (e.g., 1988 and 2008). However, in four elections, NES-measured vote change is off by more than four points. The 1964 debacle, reporting Johnson's vote at 67.5 percent of the two-party vote (compared to his actual 61.3 percent), has a lot to do with this, but several substantial errors remain even if we set aside this case (and that of 1968, since vote change involves consecutive elections). In short, since the known turnout and presidential vote choice errors in NES surveys are substantively significant, there is good reason to suspect that the errors in aggregate political characteristics related to turnout and the vote may also be nontrivial.

\section{Recalibrating NES Data}

Though unattainable as a practical matter, the goal of a survey is to obtain a representative sampling of a population that accurately measures the selected aspects of the population. When significant imperfections in representational accuracy come to light, analysts commonly attempt to correct them or to adjust the data to improve their accuracy. For instance, if we know by comparison to U.S. Census data that young African American males are greatly underrepresented in the survey, we will weight those with these characteristics in the survey more heavily to compensate for the shortfall. This is routinely done for demographic characteristics (Traugott and Katosh 1979). It would seem to be particularly important to do so for political characteristics (turnout and vote choice) that may have greater spillover effects for other political characteristics (e.g., party identification). This reweighting of the data for turnout and vote choice disparities is the data "fix" that will be applied here in order to bring the NES data into line with real-world turnout rates and presidential vote distributions.

The reweighting of the NES data is complicated by the question of whether the observable discrepancies in the aggregates of turnout and vote choice are the product of undercounting certain types of respondents (e.g., nonvoters) or the product of misreporting particular responses (e.g., nonvoters who said they voted). If the survey errors are a misreporting problem, they may be limited to the items being misreported and would not have implications for the distribution of other measures in the study. On the other hand, if the problem is one of undercounting certain types of potential respondents, then this suggests an underrepresentation of all of their related traits, attitudes, and 
behaviors. If all nonvoters were independents, for instance, and all voters were partisans, an undercount of nonvoters would mean that we were also undercounting independents. The distribution of party identification in the survey would look more partisan than is really the case. Since these are unsettled matters, assumptions must be made about them. Fortunately, there are extensive literatures (cited below) about errors in both reported turnout and reported vote choice that can provide guidance about the number and likely political characteristics of those who misreport their turnout. These provide the basis for four assumptions that undergird the reweighting or correction of the NES data.

The first assumption concerns the frequency of turnout misreporting, with actual nonvoters reporting that they had voted (Fullerton, Dixon, and Borch 2007). Voter validation studies in several elections attempted to determine whether NES's overreporting of turnout resulted from an absence of certain respondents (too few nonvoters) or from incorrect responses (nonvoters who said they voted). In the validated vote, the report of a vote or nonvote was checked against public registration and voting records. Unfortunately, the voter validation process itself was found to be imperfect. Nevertheless, from some very thorough studies, we can obtain a general sense of the extent of misreporting, and therefore the extent of the nonvoter undercount that we need to reweight to correct.

Though heavily studied, estimates of the extent of misreporting vary. Some estimates of misreporting range as high as 11 to 14 percent of respondents (Sigelman 1982; Traugott 1989). Research since the early validation studies has lowered these estimates (Presser, Traugott, and Traugott 1990, 15; Martinez 2006). ${ }^{5}$ After taking errors in validation itself into account (a misclassification of two percent), Cassel $(2004,107)$ finds that "7.1 (not 9.1) percent of respondents were overreporters in 1988." Jackman $(1999,17)$ estimates that between 84 and 89 percent of reported voters actually voted. With reported turnout rates typically in the mid-70-percent range, this is equivalent to a misreporting rate of 8 to 12 percent of all respondents. This is close to the range identified by Anderson and Silver (1986, 773). Taking all of these findings into account, a correction weighting was devised based on the assumption that the percentage of respondents misreporting was a function of the size of the NES's overreport (35 percent) and was inversely related to the turnout rate (12 percent of reported nonvoters). ${ }^{6}$ The correction process effectively makes a mid-level estimate of misreporters as constituting between 7.2 and 10.5 percent of all respondents. The mean percentage of misreporters was 8.7 percent.

5. Some uncertainty about the extent of misreporting is evident in the coding of the validated vote. Even after checking the records, it was unclear whether some respondents had been registered or had voted (Presser, Traugott, and Traugott 1990; Traugott and Presser 1992).

6. Burden (2000) claims that lower-turnout presidential elections yield lower survey-response rates and that this is associated with a greater overrepresentation of voters and a larger NES turnout gap. 
A parallel analysis was performed with different estimates of misreporting and essentially corroborated the principal analysis reported here. ${ }^{7}$ An additional separate analysis relying strictly on the vote validation studies in the 1980, 1984, and 1988 elections also produced macropartisanship measures that corresponded closely to those generated by the general correction process. ${ }^{8}$

The reweighting of NES data also assumes that the political characteristics of misreporting nonvoters, other than nonvoting (e.g., their party identification), are similar to those who reported voting. Several studies suggest that misreporters are politically similar to actual voters (Sigelman 1982; Jackson and Carsey 1999; Cassel and Sigelman 2001). Silver, Anderson, and Abramson $(1986,614)$ found that those who overreport voting are more highly educated, more politically efficacious, more concerned about the election, and have a stronger sense of civic duty and stronger partisan attachmentstraits shared with reported voters. Bernstein, Chadha, and Montjoy $(2001,41)$ similarly found that "among all nonvoters, the most likely to overreport are the more educated, the more partisan, the more religious, and those who have been contacted and asked to vote for a candidate"-again, traits associated with reported voters. Based on this research, the reweighting of the data assumes that the distribution of the partisanship of misreporters matches that of actual voters. The consequence of this assumption is conservative in that it reduces differences in partisanship between actual voters and nonvoters compared to NES's reported voters and nonvoters.

The reweighting of the NES data also requires assumptions about the source of error in the presidential vote distribution. Are the NES vote choice distribution errors the product of undercounting certain types of respondents (and all their other attributes) or of the misreporting of the vote? In examining misreports of House votes, Wright (1993) offers several observations about the possibility of misreports of the presidential vote. He speculates that misreporting more likely results from respondents being unable to recall their vote choices accurately than from deliberate deception. Anyone who would intentionally provide a false report, Wright $(1993,292)$ suggests, probably "would generally refuse to be interviewed in the first place." Elsewhere he

7. The analysis was also run with an alternate and lower assumption about misreporters (a mean of 6.1 percent of respondents). The findings were strengthened using this assumption. There are larger differences between the raw and the corrected NES data if we assume fewer misreporters and, therefore, a larger undercount of actual nonvoters.

8. The voter validation study in these three years was used to correct self-reported turnout. Those reporting that they had voted when the voter validation study indicated that there was either no record of their having voted or no record of their having been registered were recoded as not having voted. These data were then reweighted to the actual turnout and vote distribution rates. In these years, the difference between macropartisanship as measured after discounting for the estimates of misreporting and macropartisanship as measured after correcting self-reported turnout by the voter validation information differed on average by only about half a percentage point in the general public and about a third of a percentage point among voters. 
observes that the "vote for president is easily the most salient electoral decision for most people, so that, although we may expect decay in recall of presidential voting, it may not occur appreciably for weeks or months after the election" (Wright 1992, 132). Both Wright (1992) and Gronke (1992) find no evidence of misreporting in presidential voting. The fact that errors in the NES presidential vote are about the same magnitude as one might find from sampling errors also suggests that respondents are probably not misreporting their votes. In short, the correction weighting assumes that all of the errors in the presidential vote division result from an underrepresentation of certain respondents rather than misreporting of responses. The analysis proceeds under the standard weighting assumption that the underrepresented voters exhibit attributes in the same proportion as other voters for that candidate. That is, if NES data indicate that 40 percent voted for candidate $\mathrm{X}$ when we know that 45 percent actually did, and if 75 percent of candidate X's voters identified with party $\mathrm{A}$, we assume that 75 percent of the undercounted five percent also identified with party A.

The fourth assumption is that real-world turnout rates (McDonald and Popkin 2001) and presidential vote percentages (Congressional Quarterly 2005) are accurate. As the McDonald and Popkin (2001) research illustrates, what we long believed to be accurate measures of turnout were not and, as disputes in recent elections also attest, real-world vote counts are imperfect. Still, these are our best readings of the real world, and we proceed under the assumption that any errors in these real-world measures are small and random and that the official returns reflect the political reality that we are trying to understand.

With these assumptions in hand, the distribution of party identification was reweighted to bring it into accord with the known turnout and vote choice distributions. The reweighting involved seven steps for each electioncorrecting first for misreporters (reported voters who did not vote) and then weighting the recomposed groups of voters and nonvoters to simultaneously match the real-world proportions of nonvoters and voters for third-party, Democratic, and Republican presidential candidates in each party identification category. The details of the reweighting of the data and the derived weights are provided in Appendix 2.

Before proceeding to the findings, a caveat should be noted. Correcting the NES data requires the above assumptions, and they are imperfect. The exact number and characteristics of misreporters in each election are unfortunately not known. That said, the assumptions employed here are the minimum required, deal with a relatively small set of respondents, and are based on previous independent research; furthermore, the findings are confirmed when alternative assumptions are used. 


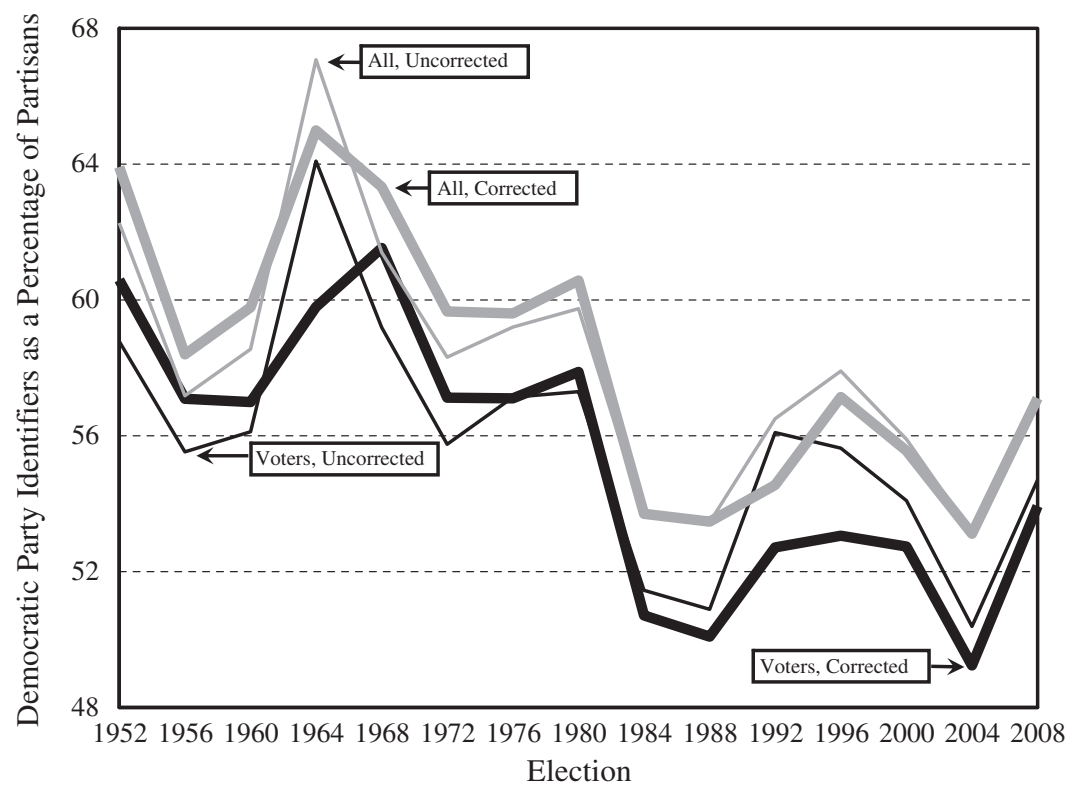

Figure 2. Macropartisanship, 1952-2008. The light lines are for all eligible voters and the dark lines are for the voters. The thin lines are uncorrected data and the thick lines are corrected data. Leaners are counted are partisans. The corrected NES data are weighted to reflect the actual division of voters and nonvoters (the VEP measure of turnout) and the partisan division of the presidential vote.

\section{THE CORRECTED NES DATA AND PARTY IDENTIFICATION}

What difference does the recalibration of the NES data make to the measure of party identification? The time series of macropartisanship from the uncorrected and corrected NES data is plotted for all respondents and for voters in figure 2. Macropartisanship is calculated as the percentage of major-party identifiers who identified with the Democratic Party (MacKuen, Erikson, and Stimson 1989, 1128). Leaners are counted as partisans (Keith et al. 1992; Petrocik 2009). As the figure shows, macropartisanship in some elections is more Democratic (1952, 1956, 1960, 1968, and 1972) and in other elections more Republican (1964, 1992, and 1996) than the uncorrected data indicated. The extent of the correction in different years also varies a good deal.

A closer comparison of the corrected and uncorrected party identification distributions reveals several important differences. As corrected, macropartisanship was more stable and less affected by short-term political forces and changed more in the Republican direction in the early 1980s. While correcting the NES data made little difference to measures of the strength of partisanship 
Table 4. Stability of Reported and Corrected Macropartisanship, 1952-2008

\begin{tabular}{lccc}
\hline Absolute Change & $\begin{array}{c}\text { Uncorrected } \\
\text { Reported } \\
\text { Between Elections for }\end{array}$ & $\begin{array}{c}\text { Corrected } \\
\text { Macropartisanship Macropartisanship Reduction }\end{array}$ & $\begin{array}{c}\text { Percent } \\
\text { Voting-Age Citizens All Elections }\end{array}$ \\
$\quad 3$ Mean & 3.18 & 2.66 & $16 \%$ \\
$\quad$ Median & 2.90 & 2.05 & $29 \%$ \\
$\quad$ Voting-Age Citizens Excluding 1984 & 2.96 & 2.34 & $21 \%$ \\
$\quad$ Mean & 2.76 & 1.67 & $39 \%$ \\
$\quad$ Median & & & \\
$\quad$ Voters All Elections & 3.10 & 2.33 & $25 \%$ \\
$\quad$ Mean & 3.35 & 2.18 & $35 \%$ \\
$\quad$ Median & & & \\
Voters Excluding 1984 & 2.88 & 1.96 & $32 \%$ \\
$\quad$ Mean & 3.25 & 1.74 & $46 \%$ \\
$\quad$ Median & & & \\
\hline
\end{tabular}

NOTE.-Macropartisanship is computed as the percentage of partisans who identified with the Democratic party. Leaners are counted as partisans. The mean and median absolute changes in the party identification gap from one election to the next are based on all 15 elections. Calculating change, however, reduces the $N$ to 14 and 13 when 1984 is excluded. The corrected data are weighted to reflect the actual divisions of voters and nonvoters (using the VEP measure of turnout) and the partisan division of the presidential vote.

among voters, it showed that the partisan dealignment of the 1970s in the public's partisanship was slightly greater and its rebound since the 1980s was slightly weaker than previously measured.

\section{THE STABILITY OF MACROPARTISANSHIP}

The stability of party identification, at both the individual and aggregate levels, has been a matter of contention for some time. Campbell et al. in The American Voter (1960) claimed a great deal of stability for individual party identification and, in Elections and the Political Order (1966), they claimed considerable stability for party identification in the aggregate, now termed macropartisanship. Later research challenged the idea that partisanship was a fixed trait of voters and characterized it as endogenous, more of a "running tally" of the voter's evaluations of the parties than an immutable attachment (Jackson 1975; Fiorina 1981). As noted above, this debate about the stability of macropartisanship continues with Erikson, MacKuen, and Stimson (2002) and Box-Steffensmeier and Smith (1996), emphasizing its changeability, and Abramson and Ostrom (1991) and Green, Palmquist, and Schickler (1998; 2001, and 2002) emphasizing its stability. 
Table 4 reports the extent of macropartisanship change between elections as measured with uncorrected and corrected NES data. Bringing the NES data into line with actual turnout and vote divisions reveals a somewhat more stable macropartisanship. The mean absolute change in macropartisanship from one election to the next was 3.18 percentage points in the uncorrected NES data and 2.66 percentage points in the corrected data, a 16-percent reduction [(3.18-2.66)/3.18]. A comparison of the medians indicates the amount of change was reduced by nearly 30 percent in the corrected data. A good deal of this difference can be traced to the 1964 election, in which the NES vote was far off the mark (and therefore macropartisanship in that year was also more seriously in error); however, the median change remained smaller (2.01 vs. 2.38) in the corrected data after both 1964 and 1968 were set aside.

Even those who contend that macropartisanship is the "unmoved mover" allow for periodic realigning changes - some real and lasting change. There is good evidence that such a realigning shift in macropartisanship occurred in the early 1980s (Meffert, Norpoth, and Ruhil 2001; Bartels 2000; Hetherington 2001). The Democrats' big lead in party identification over Republicans was seriously eroded during President Reagan's first term. Setting aside the lasting realigning change of 1984, the corrected data again exhibit greater stability than the uncorrected data. The mean macropartisanship change is cut by a fifth through the correction of the NES data (from 2.96 to 2.34).

The bottom section of table 4 examines the stability of macropartisanship among voters. As in the case of the overall electorate, correcting NES data reduces the extent of macropartisanship change between elections. Macropartisanship for voters calculated from the corrected NES data is about 25 percent more stable than in the uncorrected data. When the realigning shift of 1984 is dropped from these calculations, inter-election change among voters is reduced by about a third. In short, once the NES data are recalibrated to better reflect political reality, macropartisanship is revealed to be more stable. Macropartisanship changes from election to election, but somewhat less than the uncorrected data indicate. This non-realignment change may affect particular elections (Campbell 1997), but has not mattered much over time. After setting the 1984 realignment change aside, the total net change in macropartisanship since 1956 amounted to only half of one percentage point among voters and even less in the entire electorate.

\section{REALIGNMENT IN MACROPARTISANSHIP}

How does the correction of the NES data affect estimates of the realignmentrelated change of macropartisanship in the 1980s? Prior to 1984, Democrats held a big lead in party identification. A good portion of that lead disappeared by 1984 , when the lagging indicator of partisanship caught up with the realignment in presidential voting that had begun in the late 1960s (Carmines and Stimson 1989; Campbell 2006; Paulson 2006). Because of the historical 


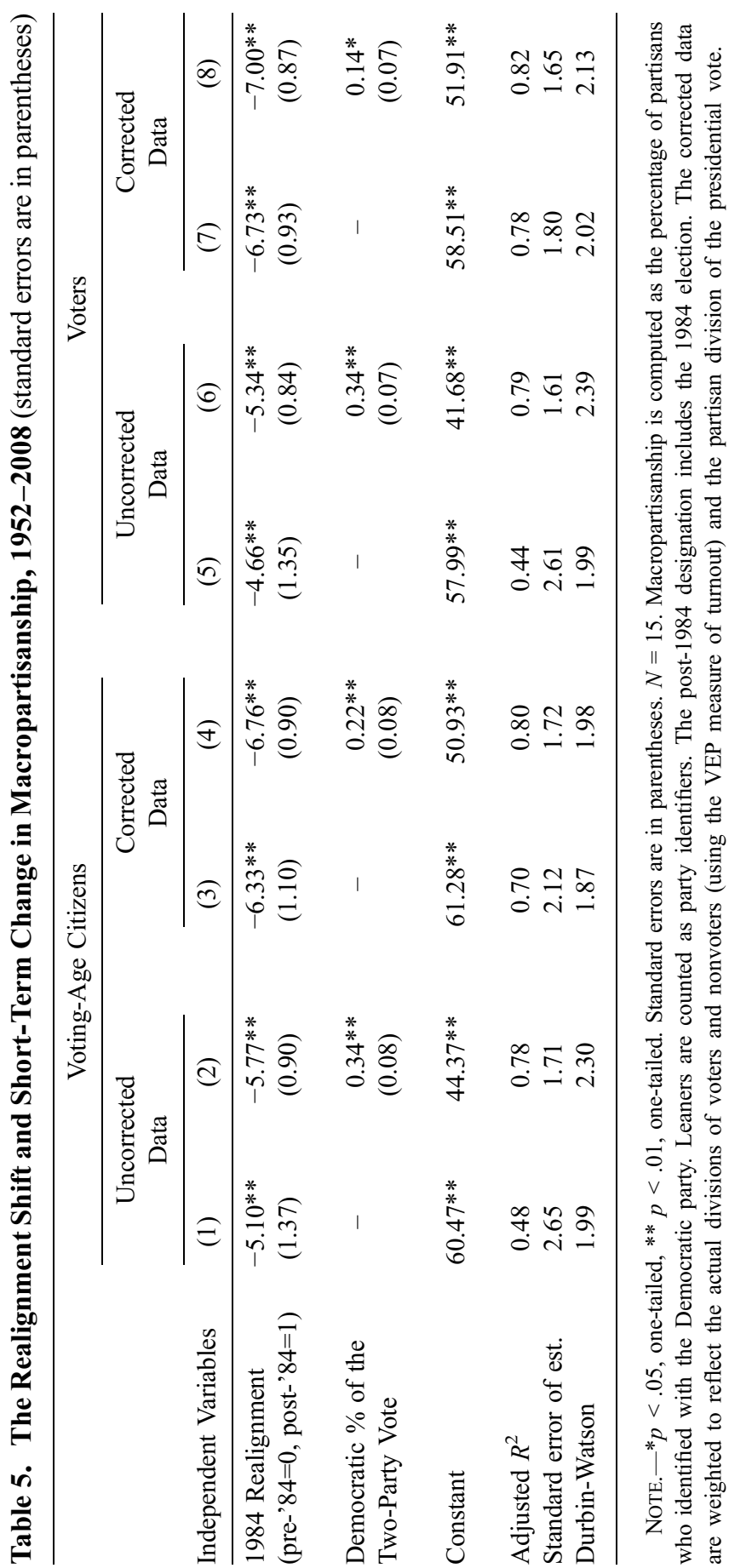


weakness of the Republican party in the South, the realignment was held off at the congressional level until 1994.

The effect of the realignment on macropartisanship is examined in table 5 . The onset of the realignment-related shift in macropartisanship is measured through a simple dummy variable taking a value of one in 1984 and elections thereafter. Prior elections are coded as zero. The even-numbered equations also include the Democratic candidate's share of the two-party vote as a summary of short-term influences that might affect macropartisanship. The first pair of regressions for both all respondents and voters is estimated using macropartisanship calculated by uncorrected NES data. The second pair uses the corrected NES data.

Each specification of the eight regressions indicates that a major shift toward the Republicans occurred in macropartisanship between 1980 and 1984. The analysis also indicates that this macropartisanship realignment has been underestimated by NES data uncorrected for turnout and presidential vote choice errors. The Republican gain in actual macropartisanship was one to 1.2 percentage points greater among all respondents and 1.7 to 2.1 points greater among voters than in the uncorrected data. This is a 17- to 24-percent increase in the shift among all respondents and a 31- to 44-percent increase in the change for voters.

In comparing the simple realignment regressions (the odd-numbered equations), the effect of correcting NES data is clear. While the realignment shift accounted for less than half of the variance in macropartisanship in the uncorrected data (as indicated by the adjusted $\mathrm{R}^{2}$ for equations 1 and 5), it accounted for 70 and 78 percent of the variance in actual macropartisanship in the public and among voters (equations 3 and 7). Most of the real variation in macropartisanship in this period was the result of the realignment shift in partisanship in the 1980s.

The regressions also examine whether macropartisanship is sensitive to the short-term political climate as reflected in the presidential vote. Short-term political conditions have an appreciable impact on macropartisanship in the uncorrected data (equations 2 and 6). Every three points of the two-party vote produced a shift of one point of macropartisanship ( $b=0.34$ in both cases). By these estimates, macropartisanship is fairly sensitive to short-term politics. In reality, once the data are corrected, macropartisanship is much less sensitive to short-term political conditions. As equation 4 indicates, it requires a 4.5-point shift in the two-party vote to generate a one-point shift in macropartisanship in the general public $(b=0.22)$. Macropartisanship among voters is even less sensitive to short-term political forces (equation 8). Though the vote coefficient is statistically significant at the 0.05 level (one-tailed), it takes a boost of about seven points in the presidential vote to shift macropartisanship one point. In short, the corrected data show that the realigning shift in the 


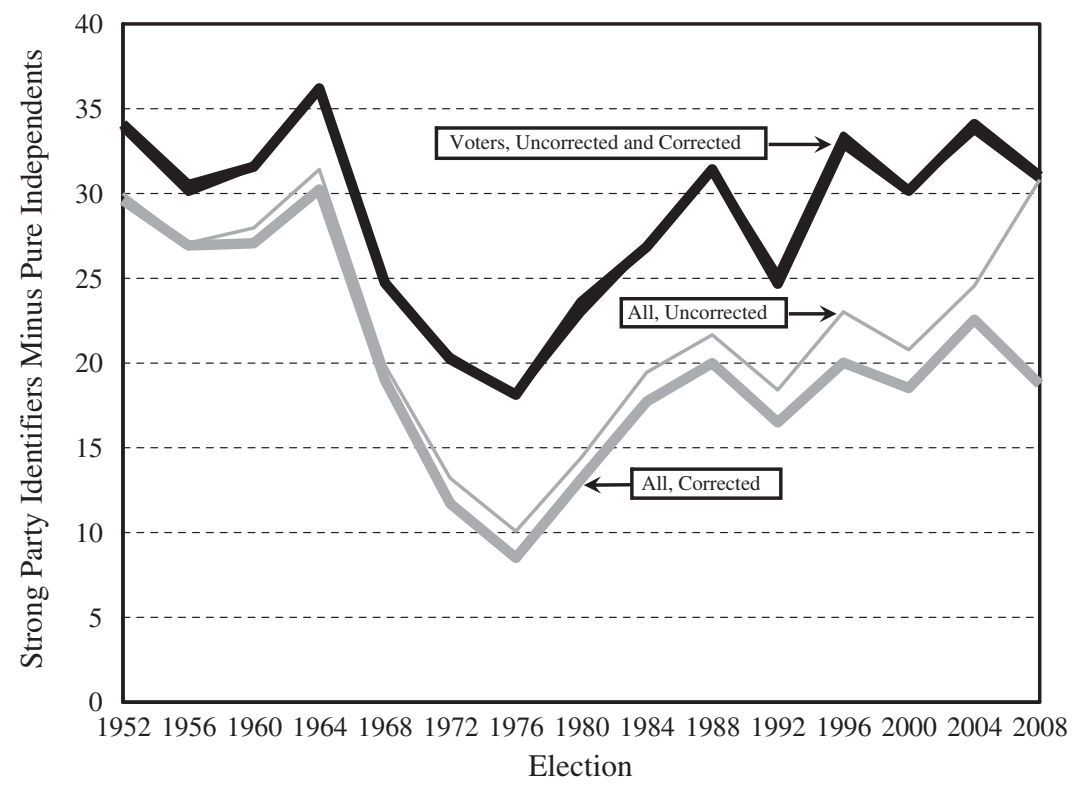

Figure 3. The Strength of Aggregate Party Identification, 1952-2008. The light lines are for all eligible voters and the dark lines are for voters. The thin lines are uncorrected data and the thick lines are corrected data. Leaners are counted as partisans. Strength of partisanship is the percentage difference between strong partisans and independents. Leaners are counted as partisans.

1980s had a larger effect on macropartisanship and that short-term political forces have been less potent in affecting macropartisanship than the uncorrected data indicated. These differences were also found when presidential approval, instead of the vote, was used to measure the short-term political climate. ${ }^{9}$

\section{THE STRENGTH OF AGGREGATE PARTISANSHIP}

Another characteristic of party identification is its strength. In the aggregate, the strength of partisanship can be measured as the difference between the percentage of strong party identifiers (both strong Democrats and strong

9. MacKuen, Erikson, and Stimson (1989) found that macropartisanship was sensitive to presidential approval and consumer sentiment, two components of the broader array of short-term forces that affect the vote. This study uses the vote itself as a more broad-based measure of all short-term forces in an election. The findings in table 5 are corroborated when using presidential approval (centered at 50 percent and oriented toward the Democrats) instead of the presidential vote. The effect of approval drops from 0.14 to 0.08 for all respondents and from 0.15 to 0.05 for voters when macropartisanship is measured using the corrected data. The coefficients are statistically significant at $p<.05$, one-tailed except for the corrected data analysis for voters. 
Republicans) and the percentage of pure independents. Figure 3 displays the uncorrected and corrected aggregate partisan strength measure for both all voting eligible citizens and voters. As the figure shows, strong partisans have consistently outnumbered independents, especially among voters. Apart from this constancy, partisanship weakened during the dealignment of the 1970s and rebounded beginning in the 1980s.

While there were some differences between the corrected and uncorrected measures of aggregate partisan strength, what is most noteworthy is that the differences were generally quite small, especially among voters. It appears that the effect of reassigning more partisan misreporters to the ranks of nonvoters partially offsets the effect of weighting nonvoters more heavily to bring their number into line with the lower real turnout rates. Where the correction made some difference was in the general public's strength of partisanship in elections since the 1970s. The corrected data indicated that the public was slightly less partisan than the NES data suggested and that the rebound in partisanship was not quite as strong in the general public as the uncorrected data indicated. Partisanship is clearly back to the 1950s levels among voters, but not for the public as a whole. Nonvoters in recent years remain much less partisan than the nonvoters of the 1950s.

\section{Discussion}

NES data provide the basis for much of what we know about electoral behavior. It is important to remember, however, that these data are imperfect measures of political reality, rather than political reality itself. With most surveys, this distinction might be noted in passing and, lacking an alternative, research would proceed as though there were no distinction. With a survey conducted during an election, however, there are benchmarks to assess the survey's accuracy - specifically, turnout and the vote division. Fortunately, where there are known inaccuracies, there are also ways of providing a reweighting "fix." While this fix is imperfect (reflected in the required assumptions), it should reduce the gap between the real-world benchmarks and the survey. This fix, of course, is of little consequence for the benchmark characteristics themselves. We already know what the turnout rates and presidential vote divisions are without the benefit of NES data, corrected or not. Where the correction may be important is for respondent characteristics that are closely related to turnout or presidential vote choice and that lack any real-world benchmark for comparison. Party identification fits this description.

As the preceding analysis demonstrated, correcting NES data for their known errors in aggregate turnout and the presidential vote division did not produce drastic changes in the distribution of party identification, for either macropartisanship or the aggregate strength of partisanship. For the most part, the corrections changed these measures by a point or two here and there. However, though small in absolute terms, these corrections made more substan- 
tial changes in the time series and clarified the dynamics of macropartisanship and the strength of partisanship.

In broad terms, these changes brought the data more into line with the portrait of partisanship painted by The American Voter (Campbell et al. 1960) and recently reconfirmed in The American Voter Revisited (Lewis-Beck et al. 2008, 136). Macropartisanship is less fluid and less sensitive to short-term forces than the uncorrected data had suggested. This lends support to the earlier findings of Abramson and Ostrom (1991) and Green, Palmquist, and Schickler (2002). The surveys were more sensitive to short-term forces than was the actual partisanship of the electorate. Most of the variation in macropartisanship over this period was the result of the realignment-related shift in partisanship between the 1980 and 1984 elections.

While this research has focused on how errors in the NES have affected the measurement of macropartisanship, the study has broader implications for other characteristics closely associated with either turnout or the presidential vote, as well as for other surveys on which reality checks could be conducted. Studies of the relationship between preference polls and the vote may be instructive on this point. The historical relationship between pre-election polls and the later vote suggests that the polls should not be accepted at face value as accurate reflections of the vote. They can be adjusted to be more accurate by taking their historical relationship with the vote into account (Campbell 1996; Wlezien and Erikson 2002; and Erikson and Wlezien 2008). By the same token, when benchmarks are available, analysts may be able to obtain a more accurate picture of public opinion by adjusting survey data to better reflect this reality.

\section{Appendix 1:}

AMERICAN NATIONAL ELECTION STUDY CUMULATIVE DATA FILE, 1948-2004, AND THE 2008 STUDY

The American National Election Studies (NES) have been conducted in every presidential and most midterm election years since 1948. Only the 14 national surveys conducted in presidential years since 1952 to 2004 are used here. Data from the 2008 NES study were also examined. Since many of the early NES studies were conducted well before AAPOR standards were promulgated, documentation of these studies is somewhat sketchy and incomplete. Much of the information assembled below was obtained from the NES website (http://www.electionstudies.org/overview/dataqual.htm\#tab1) and through the help of Daniel Donakowski of the NES. Additional information about NES data is available at the NES website.

The sampling frames of the studies were defined to include all U.S. citizens of voting age on or before Election Day who resided in U.S. households (including civilian households on military bases) in the 48 coterminous states, excluding individuals living in group quarters, military facilities, and 
institutional populations. In the 1978 and 1980 studies, residents of Washington, D.C., were also excluded from the sampling frame.

The sampling design has varied since 1952. The documentation for the cumulative file indicates that "the most common NES study design has been a cross-section, equal probability sample. These designs are typically 'selfweighting'-i.e., the respondents do not need to be weighted to compensate for unequal probabilities of selection in order to restore the 'representativeness' of the sample. In several years, however, NES departed from this standard design and 'oversampled' certain groups (African Americans in 1964 and 1968, for example). In other years, the Election Study combined a panel re-interview with a cross-section design (as in 1974, for example)." Beginning with the 1978 midterm and the 1980 presidential election year studies, the primary sampling area was changed to the congressional district, though the total sample was still drawn to constitute a representative national cross-section.

Response rates in the surveys varied between 59.5 (2008) and 85.0 (1956) percent. A response rate was not available for the 1960 study. The median response rate was 72 percent. NES calculated response rates as the number of completed interviews as a percentage of the sample size. The rates were 77.2 in 1952, 85.0 in 1956, 59.5 in 1964, 77.4 in 1968, 75.0 in 1972, 70.4 in 1976, 71.8 in 1980, 72.1 in 1984, 70.5 in 1988, 74.1 in 1992, 59.8 in 1996, 60.5 in 2000, 66.1 in 2004, and 59.5 in 2008. The refusal rate for the 12 elections in which it was available was a median of 16 percent, though it was as high as 31 percent in 2000.

Each NES presidential election study has a pre-election survey conducted during the two months leading up to Election Day and a post-election survey conducted during the two months after Election Day. Interviewing for the preelection wave generally began in early September of the election year and ran up to the day before the election. The post-election wave began the day after the election and often extended into January.

\section{QUESTION WORDING}

This study employed three variables from the NES: party identification, turnout, and presidential vote choice.

Party Identification Measure: Party identification (VCF0301 in the cumulative file and from V083097, V083098a, and V083098b in the 2008 data) is the traditional measure composed from responses to an initial question and two branching questions: "Generally speaking, do you usually think of yourself as a Republican, a Democrat, an Independent, or what? (If Republican or Democrat) Would you call yourself a strong (Republican/Democrat) or a not very 
strong (Republican/Democrat)? (If Independent, Other [1966 and later: or No Preference]) Do you think of yourself as closer to the Republican or Democratic party?" The summarized party identification responses were scaled as (1) Strong Democrat; (2) Weak Democrat; (3) Independent-Democrat; (4) Independent-Independent; (5) Independent-Republican; (6) Weak Republican; (7) Strong Republican; and (9) Apolitical.

Turnout measure: The voter turnout question (VCF0702 in the cumulative data and V085036x in 2008) in presidential elections changed over the years. From 1952 to 1996 and version 1 in 2004, the question was "In talking to people about the election, we (1972 and later: often) find that a lot of people weren't able to vote because they weren't registered or they were sick or they just didn't have time. (1956 and 1960: How about you, did you vote this time?) (1964 and 1968: How about you, did you vote this time, or did something keep you from voting?) (1972 and 1976: How about you, did you vote in the elections this fall?) (1978 and later: How about you, did you vote in the elections this November?) In 2000 and version 2 in 2004, the turnout question was worded as "In talking to people about elections, we often find that a lot of people were not able to vote because they weren't registered, they were sick, or they just didn't have time. Which of the following statements best describes you: One, I did not vote (in the election this November); Two, I thought about voting this time, but didn't; Three, I usually vote, but didn't this time; or Four, I am sure I voted?" Responses were then recoded as (1) No, did not vote; or (2) Yes, voted.

In 2008, version 1 of the turnout question used the version 2 wording of 2004. Version 2 of the turnout question in 2008 was worded as "In asking people about elections, we often find that a lot of people were not able to vote because they weren't registered, they were sick, they didn't have time, or something else happened to prevent them from voting. And sometimes, people who usually vote or who planned to vote forget that something unusual happened on Election Day one year that prevented them from voting that time. So, please think carefully for a minute about the recent elections, and other past elections in which you may have voted, and answer the following questions about your voting behavior." After then being asked about whether they usually vote and whether they had planned on voting, respondents were asked: "Which one of the following best describes what you did in the elections that were held November 4? (1) Definitely did not vote in the elections; (2) Definitely voted in person at a polling place on Election Day; (3) Definitely voted in person at a polling place before Election Day; (4) Definitely voted by mailing a ballot to elections officials before the election; (5) Definitely voted in some other way; and (6) Not completely sure whether you voted or not." Respondents who indicated that they were unsure of whether they had voted 
were then asked: "If you had to guess, would you say that you probably did vote in the elections, or probably did not vote in the elections?" The responses were coded as (0) Did not vote in November 2008; or (1) Voted in November 2008 .

Presidential Vote Measure: The presidential vote question (VCF0705 in the cumulative data and V085044a in 2008) also changed slightly over the years. From 1952 to 1964, respondents who reported that they had voted were asked: "Who did you vote for President?" From 1968 to 1976, reported voters were asked: "Who did you vote for in the election for President?" From 1980 to 2008, reported voters were asked: "How about the election for President? Did you vote for a candidate for President? (If yes) Who did you vote for?" With the exceptions of tables 1 through 3 , the coding used for responses to these questions was (1) Democrat; (2) Republican; (3) Other (including 3rd/minorparty candidates and write-ins). In tables 1 through 3 , only votes for the majorparty candidates were examined (VCF0704).

\section{Appendix 2}

The reweighting of the NES data to bring it into line with both actual turnout rates and presidential vote divisions involved seven steps.

First, the distribution of party identification was obtained for four groups of NES respondents for each election: (1) reported nonvoters; (2) reported presidential voters for minor presidential candidates; (3) reported voters for the Democratic party's candidate; and (4) reported voters for the Republican party's candidate. Respondents were then sorted by their vote into 32 different "Party ID by Vote" categories for each of the 15 presidential election years from 1952 to 2008. The 32 categories reflect eight different party identification categories (apolitical, strong Democrats, weak Democrats, leaning Democrats, Independents, leaning Republicans, weak Republicans, and strong Republicans) for the four types of respondents identified above (reported nonvoters, minor-party voters, voters for the Democrat, and voters for the Republican).

The second step estimated the percentage of respondents who were misreporters (those claiming to have voted but who did not vote) in each year. As noted above, based on past studies, this was estimated based on the NES study's turnout gap and the percentage of reported nonvoters. Between 7.2 and 10.5 percent of respondents were estimated as misreporters. ${ }^{10}$ This trans-

10. The estimated percentage of all respondents who were misreporters or nonvoters who claim to have voted are as follows: 7.2 in $1952,7.7$ in 1956, 7.8 in 1960, 7.9 in 1964, 7.8 in $1968,8.9$ in 1972, 9.2 in 1976, 9.3 in 1980, 9.4 in 1984, 9.4 in 1988, 8.9 in 1992, 10.5 in 1996, 9.7 in 2000, 8.5 in 2004 , and 8.2 in 2008 . These are rounded percentages. 
lates into between 85 and 90 percent of reported voters being recognized as actual voters or between 21 and 27 percent of actual nonvoters being misreporters. These rates are middle-range assumptions about the extent of misreporting. A lower misreporting rate (a mean of 6.1 percent) also was examined to test the robustness of the findings and confirmed those findings. The percentage of misreporters then was converted to an actual number based on the size of the sample. In 2004, for instance, about 8.5 percent of all respondents were estimated as being misreporters. This amounted to about 88 of the nearly 1,032 respondents in the survey. These are rounded numbers after the initial weighting of the data using NES's recommended weights.

Third, based on the second assumption above (that the distribution of a political variable among misreporters was the same proportion as it was among reported voters), the distribution of the party identification of misreporters was simulated and added to the distribution of the reported nonvoters to arrive at the full distribution of party identification for actual nonvoters. Again using the 2004 example and under the assumption that misreporters have the same distribution of partisanship as reported voters in 2004, the 88 misreporters were apportioned as 19 strong Republicans, 13 weak Republicans, 10 leaning Republicans, five Independents, 14 leaning Democrats, 12 weak Democrats, 16 strong Democrats, and no apoliticals. These total to 89 because of rounding.

Fourth, to avoid double-counting misreporters, the misreporters were deducted proportionately from the three distributions of reported voters (reported voters for minor candidates, voters for the Democrat, and voters for the Republican). In essence, this converted these from distributions of party identification among three groups of reported voters to distributions of party identification among three groups of actual voters. Following the 2004 example, the approximate 88 misreporters were subtracted from their reported voter groups and added to the appropriate party identification category of reported nonvoters. The estimated 19 strong Republican misreporters (noted in the third step) were thus added to the 10 strong Republicans who were reported nonvoters to yield about 29 strong Republicans who were actual nonvoters in 2004. The 19 strong Republicans were subtracted proportionately from the ranks of strong Republicans who reported that they voted for the Republican, the Democrat, or a third-party candidate. Since about 97 percent of strong Republicans who reported voting claimed that they voted for the Republican presidential candidate in 2004, most of these 19 were subtracted from the approximately 164 loyal strong Republicans who reported having voted. This left us with about 146 loyal strong Republicans who actually voted.

Fifth, the total percentage of cases within each of the four NES recomposed groups (actual nonvoters from step three and actual voters for minor-party, Democratic party, and Republican party candidates) was then calculated.

Sixth, the weights for each of the four NES recomposed groups were calculated as the ratios of their real-world percentage of the electorate divided by their percentage of the NES sample. The real-world percentages were drawn 
Table A-1. Weights for the Regrouped NES Data, 1952-2008

\begin{tabular}{lcccc}
\hline \multicolumn{5}{c}{ Weights for Regrouped Data } \\
\hline Election & Nonvoters & $\begin{array}{c}\text { Minor } \\
\text { Candidate Voters }\end{array}$ & $\begin{array}{c}\text { Democratic } \\
\text { Candidate Voters }\end{array}$ & $\begin{array}{c}\text { Republican } \\
\text { Candidate Voters }\end{array}$ \\
\hline 1952 & 1.1337 & 1.7929 & 0.9902 & 0.8885 \\
1956 & 1.1399 & 1.9379 & 0.9670 & 0.8912 \\
1960 & 1.2555 & 1.3087 & 0.9149 & 0.8748 \\
1964 & 1.2322 & 2.3753 & 0.8135 & 1.0712 \\
1968 & 1.1888 & 1.0991 & 0.9498 & 0.8294 \\
1972 & 1.1933 & 1.4925 & 0.9438 & 0.8468 \\
1976 & 1.1921 & 0.9763 & 0.8799 & 0.8822 \\
1980 & 1.1890 & 0.7431 & 0.9176 & 0.8803 \\
1984 & 1.2190 & 0.6229 & 0.8543 & 0.8905 \\
1988 & 1.1728 & 0.7470 & 0.8661 & 0.9020 \\
1992 & 1.2338 & 0.9308 & 0.7942 & 0.9723 \\
1996 & 1.2637 & 0.9218 & 0.7763 & 0.9008 \\
2000 & 1.2334 & 0.8465 & 0.8332 & 0.8950 \\
2004 & 1.2439 & 0.5328 & 0.8675 & 0.9162 \\
2008 & 1.2463 & 0.6766 & 0.8794 & 0.9140 \\
\hline
\end{tabular}

NOTE.-The weights are determined after the NES data were regrouped to classify correctly misreporters as nonvoters. The weights are the ratio of the actual percentage in a group to the NES percentage of respondents in a group (after regrouping). The weights above are rounded.

from turnout rates as a percentage of the voting-eligible population, as calculated by McDonald and Popkin (2001; McDonald 2009) and the presidential vote distributions in Congressional Quarterly's Guide to U.S. Elections (2005, 706-19). For example, in 2004, 60.34 percent of the voting-eligible population (VEP) voted (McDonald 2009). This meant that the real-world percentage of nonvoters was 39.66 percent and the real-world percentage of voters was 60.34 percent. With President Bush receiving 50.73 percent of the vote, this was equal to about 30.61 percent of the VEP $(0.5073 \times 60.34)$. Senator Kerry's 48.27 percent of the total vote was 29.12 percent of the VEP. The vote for minor-party candidates of 1.00 percent of voters was 0.60 percent of the VEP. The reconstituted NES groups for 2004 (correcting for the misreported turnout problem dealt with in steps two through five above) were 31.88 percent of nonvoters, 1.13 percent of third-party voters, 33.57 percent of Kerry voters, and 33.41 percent of Bush voters. ${ }^{11}$ The weights for the re-

11. The careful reader may observe that the percentage of Kerry voters in the recomposed groups is greater than the percentage of Bush voters. This error is not the result of the recomposition, but reflects the reported vote division of the NES sample of respondents indicating a party identification. The NES weighted data indicated 387.7 votes for Bush and 389.6 percent of votes for Kerry among those answering the party identification questions. This includes all Independents as well as Democratic and Republican party identifiers. 
composed NES data in 2004 were then calculated as 1.24 for nonvoters (39.66/31.88), 0.53 for third-party-candidate voters $(0.60 / 1.13), 0.87$ for Democratic voters (29.12/33.57), and 0.92 for Republican voters (30.61/ 33.41). The full set of weights is presented in table A-1.

The seventh and final step was to multiply the number of cases in the 32 recomposed "Party ID by Vote" groups by the appropriate weights. For example, cases in each of the eight party identification categories for NES actual nonvoters were multiplied by the nonvoter weight. The eight party identification categories for voters for minor-party candidates were multiplied by the minor-party vote weight and so on for the party identification categories of Democratic voters and Republican voters. The party identification categories were then combined across the four recomposed groups (e.g., strong Democrats among nonvoters, among voters for a minor-party candidate, among voters for the Democratic candidate, and among voters for the Republican candidate) to determine the total number in each party identification category. These were then computed as percentages. The distribution of party identification among voters followed the same sequence, except actual nonvoters were omitted when reassembling the eight party identification categories.

\section{References}

Abramowitz, Alan I. 2004. Voice of the People: Elections and Voting in the United States. New York: McGraw Hill.

Abramson, Paul R., and John H. Aldrich. 1982. "The Decline of Electoral Participation in America." American Political Science Review 76(3):502-21.

Abramson, Paul R., John H. Aldrich, and David W. Rohde. 2005. Continuity and Change in American National Elections. Washington, D.C.: CQ Press.

Abramson, Paul R., and Charles W. Ostrom Jr. 1991. "Macropartisanship: An Empirical Reassessment." American Political Science Review 85(1):181-92.

Anderson, Barbara, and Brian D. Silver. 1986. "Measurement and Mismeasurement of the Validity of the Self-Reported Vote." American Journal of Political Science 30(4):771-85.

Asher, Herbert. 2007. Polling and the Public: What Every Citizen Should Know. 7th ed. Washington, D.C.: CQ Press.

Bartels, Larry M. 2000. "Partisanship and Voting Behavior, 1952-1996." American Journal of Political Science 44(1):35-50.

Bernstein, Robert, Anita Chadha, and Robert Montjoy. 2001. "Overreporting Voting: Why It Happens and Why It Matters." Public Opinion Quarterly 65(1):22-44.

Box-Steffensmeier, Janet M., and Renee M. Smith. 1996. "The Dynamics of Aggregate Partisanship." American Political Science Review 90(3):567-80.

Burden, Barry C. 2000. "Voter Turnout and the National Election Studies." Political Analysis 8 (4):389-98.

Burnham, Walter Dean. 1970. Critical Elections and the Mainsprings of American Politics. New York: W. W. Norton.

Campbell, Angus, Philip E. Converse, Warren E. Miller, and Donald E. Stokes. 1960. The American Voter. New York: Wiley.

Campbell, Angus, Philip E. Converse, Warren E. Miller, and Donald E. Stokes, eds. 1966. Elections and the Political Order. New York: Wiley. 
Campbell, James E. 1996. "Polls and Votes: The Trial-Heat Presidential Election Forecasting Model, Certainty, and Political Campaigns." American Politics Quarterly 24(4):408-33.

1997. The Presidential Pulse of Congressional Election. 2nd ed. Lexington, KY: University Press of Kentucky.

. 2006. "Party Systems and Realignments in the United States, 1868-2004." Social Science History 30(3):359-86.

Carmines, Edward G., and James A. Stimson. 1989. Issue Evolution. Princeton, NJ: Princeton University Press.

Cassel, Carol A. 2004. "Voting Records and Validated Voting Studies." Public Opinion Quarterly 68(1):102-8.

Cassel, Carol A., and Lee Sigelman. 2001. "Misreporters in Candidate Choice Models." Political Research Quarterly 54(3):643-55.

Clausen, Aage R. 1968-69. "Response Validity: Vote Report.” Public Opinion Quarterly 32 (4):588-606.

Congressional Quarterly. 2005. Guide to U.S. Elections. 5th ed. Washington, D.C.: CQ Press.

Converse, Philip E. 1966. "The Concept of the "Normal Vote." In Elections and the Political Order, eds. Campbell Angus, Philip E. Converse, Warren E. Miller and Donald E. Stokes. New York: Wiley.

Crespi, Irving. 1988. Pre-Election Polling: Sources of Accuracy and Error. New York: Russell Sage.

Erikson, Robert S., Michael B. MacKuen, and James A. Stimson. 1989. "What Moves Macropartisanship? A Response to Green, Palmquist, and Schickler.” American Political Science Review 92(4):901-12.

. 2002. The Macro Polity. New York: Cambridge University Press.

Erikson, Robert S., and Christopher Wlezien. 2008. "Are Political Markets Really Superior to Polls as Election Predictors?” Public Opinion Quarterly 72(2):190-215.

Fiorina, Morris P. 1981. Retrospective Voting in American National Elections. New Haven, CT: Yale University Press.

Fullerton, Andrew S., Jeffrey C. Dixon, and Casey Borch. 2007. "Bringing Registration into Models of Overreporting." Public Opinion Quarterly 71(4):649-60.

Green, Donald P., Bradley L. Palmquist, and Eric Schickler. 1998. "Macropartisanship: A Replication and Critique." American Political Science Review 92(4):883-99.

- 2001. "Partisan Stability: Evidence from Aggregate Data." In Controversies in Voting Behavior, eds. Richard G. Neimi and Herbert F. Weisberg, 4th ed. Washington, D.C: CQ Press. 2002. Partisan Hearts and Minds. New Haven, CT: Yale University Press.

Gronke, Paul. 1992. "Overreporting the Vote in the 1988 Senate Election Study: A Response to Wright." Legislative Studies Quarterly 17(1):113-29.

Hetherington, Marc. 2001. "Resurgent Mass Partisanship: The Role of Elite Polarization." American Political Science Review 95(3):619-31.

Jackman, Simon. 1999. "Correcting Surveys for Non-Response and Measurement Error Using Auxiliary Information." Electoral Studies 18(1):7-27.

Jackson, John E. 1975. "Issues, Party Choices, and Presidential Votes." American Journal of Political Science 19(2):161-85.

Jackson, Robert A., and Thomas M. Carsey. 1999. "Misreport of Vote Choice." Presented at the American Political Science Association Meeting, Atlanta, GA.

Jamieson, Kathleen Hall. 2000. Everything You Think You Know about Politics, and Why You're Wrong. New York: Basic Books.

Keith, Bruce E., David B. Magleby, Candice J. Nelson, Elizabeth Orr, Mark C. Westlye, and Raymond E. Wolfinger. 1992. The Myth of the Independent Voter. Berkeley, CA: University of California Press.

Key, V. O. Jr. 1955. "A Theory of Critical Elections.” Journal of Politics 17(1):3-18. - 1959. "Secular Realignment and the Party System." Journal of Politics 21(2):198-210. 
Leip, Dave. 2009. Atlas of U.S. Presidential Elections. Available at: http://uselectionatlas.org/ (accessed July 1, 2009).

Lewis-Beck, Michael S., William G. Jacoby, Helmut Norpoth, and Herbert F. Weisberg. 2008. The American Voter Revisited. Ann Arbor, MI: University of Michigan Press.

MacKuen, Michael B., Robert S. Erikson, and James A. Stimson. 1989. "Macropartisanship." American Political Science Review 83(4):1125-42.

Martinez, Michael D. 2006. "If Turnout Is So Low, Why Do So Many People Say They Vote." Presented at the Southern Political Science Association Meeting, Atlanta, GA.

Martinez, Michael D., and Jeff Gill. 2005. "The Effects of Turnout on Partisan Outcomes in U.S. Presidential Elections 1960-2000.” Journal of Politics 67(4):1248-74.

McDonald, Michael P. 2007. "The True Electorate: A Cross-Validation of Voter Registration Files and Election Survey Demographics." Public Opinion Quarterly 71(4):588-602. 2009. Available at: http://elections.gmu.edu/voter_turnout.htm (accessed June 19, 2009).

McDonald, Michael P., and Samuel L. Popkin. 2001. "The Myth of the Vanishing Voter." American Political Science Review 95(4):963-74.

Meffert, Michael F., Helmut Norpoth, and Anirudh V. S. Ruhil. 2001. "Realignment and Macropartisanship." American Political Science Review 95(4):953-62.

Paulson, Arthur. 2006. Electoral Realignment and the Outlook for American Democracy. Boston, MA: Northeastern University Press.

Petrocik, John Richard. 2009. "Measuring Party Support: Leaners Are Not Independents." Electoral Studies 28(4):562-72.

Presser, Stanley, Michael W. Traugott, and Santa Traugott. 1990. "Vote 'Over' Reporting in Surveys: The Record or the Respondents?" Presented at the International Conference on Measurement Errors, Tucson, AZ.

Rosenstone, Steven J., and John Mark Hansen. 2003. Mobilization, Participation, and Democracy in America. New York: Longman.

Sigelman, Lee. 1982. "The Nonvoting Voter in Voting Research." American Journal of Political Science 26(1):47-56.

Silver, Brian, Barbara A. Anderson, and Paul R. Abramson. 1986. "Who Overreports Voting?" American Political Science Review 80(2):613-24.

Stimson, James A. 2004. Tides of Consent: How Public Opinion Shapes American Politics. New York: Cambridge University Press.

Traugott, Michael W., and John P. Katosh. 1979. "Response Validity in Surveys of Voting Behavior." Public Opinion Quarterly 43(3):359-77.

Traugott, Michael W., and Stanley Presser. 1992. "Revalidation of Self-Reported Vote." Presented at the American Association of Public Opinion Research, St. Petersburg Beach, FL.

Traugott, Santa. 1989. "Validating Self-Reported Vote: 1964-1988." National Election Study Technical Report 34. Ann Arbor, MI: University of Michigan.

Wlezien, Christopher, and Robert S. Erikson. 2002. "The Timeline of Presidential Election Campaigns." Journal of Politics 64(4):969-93.

Wright, Gerald C. 1992. "Reported versus Actual Vote: There Is a Difference and It Matters." Legislative Studies Quarterly 17(1):131-42.

— 1993. "Errors in Measuring Vote Choice in the National Election Studies, 1952-88." American Journal of Political Science 37(1):291-316. 